\title{
Detection of calicivirus from fecal samples from children with acute gastroenteritis in the West Central region of Brazil
}

\author{
Ana Maria Tavares Borges, José Marcus Sócrates Teixeira*, \\ Paulo Sérgio Sucasas da Costa**, Loreny Gimenes Giugliano***, Fabíola Souza Fiaccadori, \\ Rachel de Carvalho e Franco, Wilia Marta Elsner Diederichsen de Brito, José Paulo \\ Gagliardi Leite****, Divina das Dores de Paula Cardoso/ ${ }^{+}$
}

\begin{abstract}
Laboratório de Virologia, Instituto de Patologia Tropical e Saúde Pública **Faculdade de Medicina, Universidade Federal de Goiás, Rua 235, esquina com $1^{\text {a }}$ Avenida sem No , Setor Universitário, 74605-050 Goiânia, GO, Brasil *Instituto de Saúde do Distrito Federal, Brasília, DF, Brasil ***Departamento de Biologia Celular, Universidade de Brasília, Brasília, DF, Brasil ****Laboratório de Virologia, Instituto Oswaldo Cruz-Fiocruz, Rio de Janeiro, RJ, Brasil
\end{abstract}

The objective of this study was to describe the circulation of caliciviruses in the West Central region of Brazil and its correlation with children's gender and age, as well as with the year and months of the sample collection. Reverse transcriptase-polymerase chain reaction was performed to detect the human calicivirus genome in 1006 fecal samples that were collected in Goiania $(n=696)$ and Brasilia $(n=310)$. Viral RNA was detected in $8.6 \%$ of the samples. No significant difference in viral prevalence was found regarding gender, age or year of the sample. However, it was observed that in Goiânia, there is a higher incidence of caliciviruses from September to March. The analysis employing three primer pairs demonstrated that the Ni/E3 or JV12/13 primer pairs, which detect norovirus (NoV), detected 41 positive samples while the 289/290 primer pair, which detects NoV or sapovirus, detected the remaining 46 samples. Calicivirus circulates in the West Central region of Brazil and for better detection of this virus it is important to use more than one primer pair. Also, we conclude that the seasonality presented by this virus is related to higher humidity in the period.

Key words: calicivirus - acute gastroenteritis - reverse transcriptase-polymerase chain reaction - Brazil

Viral gastroenteritis is a common disease in humans, and different agents such as rotavirus, astrovirus, adenovirus and calicivirus ( $\mathrm{HuCV}$ ) have been associated with the disease (Glass et al. 2000). HuCVs are part of the Caliciviridae family, which includes four genera, Norovirus (NoV), Sapovirus (SaV), Vesivirus, and Lagovirus. The first two have been known to infect humans and present two major genomic structure differences. The NoV genome is organized in three open reading frames (ORFs): ORF1 codes for a non-structural polyprotein and ORF2 and ORF3 codes for the capsid protein and for a small structural protein, respectively. $\mathrm{SaV}$ genomes present only two ORFs. The non-structural polyprotein and the capsid protein are coded in the same ORF (ORF1) while the small structural protein is coded by ORF2 (Green et al. 2000, Koopmans et al. 2002).

Studies carried out using reverse transcriptase-polymerase chain reaction (RT-PCR) and genomic sequencing has shown great genomic diversity for these viruses. Thus, classification systems including genomic variants have been proposed. In this way the suggestion is that the genus currently known as Norovirus is composed of two genogroups, I and II, with five and nine genetic groups, respectively (Ando et al. 2000, Green et al. 2000). In

\footnotetext{
Financial support: $\mathrm{CNPq}$

${ }^{+}$Corresponding author: dcardoso@iptsp.ufg.br

Received 16 March 2006

Accepted 6 September 2006
}

addition, Farkas et al. (2004) suggest that $\mathrm{SaV}$ may be as diverse as NoV and a new antigenically different strain commonly occurs in a community.

The great genetic diversity presented by caliciviruses makes it difficult to develop a universal system to detect them. For virus detection, RT-PCR has been extensively used, employing primers designed for different regions of the genome. The most frequently used primers have been designed for the region of the RNA polymerase, which is conserved between the genetic groups (Green et al. 1995, 1997, Gray et al. 1997, Jiang et al. 1999, Guo et al. 2001, Koopmans et al. 2002).

To our knowledge the present study is the first to focus on caliciviruses in the West Central region of Brazil and presents results of viruses detected in fecal samples from children with acute gastroenteritis.

\section{MATERIAL AND METHODS}

Subject - Fecal samples were collected from children up to five years of age, with acute gastroenteritis in public hospitals in the cities of Goiânia, Goiás, and Brasília, Distrito Federal. A total of 696 samples were collected in Goiânia, from 1998 to 2002; 310 fecal samples were collected in Brasília, from 1994 to 1996 and from 2000 to 2002. All samples from Goiânia were collect "in nature" while of the samples collected in Brasília, 156 were collected "in nature" and 154 by rectal swab. From 1006 fecal samples, 571 were from males and 430 from females. No gender information was obtained from five children from Brasília. These samples were stored at $-20^{\circ} \mathrm{C}$ and were previously tested for group A rotavirus, adenovirus, and astrovirus, 
and in this way, were frozen and thawed more the once.

The samples were collected from children after written consent from their parents/legal guardians. Also, ethical approval was obtained from the Research Ethics Committee of the Federal University of Goiás/No.004/ 2000.

Methodology - For the detection of calicivirus, the ssRNA was extracted from $20 \%$ fecal suspension by the glass powder method, using guanidinium thiocyanate as described by Boom et al. (1990) with modifications (Cardoso et al. 2002). The cDNA was obtained using the random primer $\mathrm{pd}(\mathrm{N})_{6}(20 \mu \mathrm{M})$ (Amersham Biosciences), RT MMLV (200 U/ $\mu$ l) (USB) and ribonuclease inhibitor $(20 \mathrm{U} / \mu \mathrm{l})$ (Invitrogen). The amplification reaction was carried out using Taq DNA polymerase (1,5 U/ $\mu \mathrm{l})$ (Invitrogen) and the primer pairs Ni/E3 (Green et al. 1995), 289/290 (Jiang et al. 1999). When results with the two primer pairs were inconclusive, the pair primer JV12/13 (Vinjé et al. 1997 ) was used. The PCR products were resolved by $2 \%$ agarose gel electrophoresis, and stained with ethidium bromide. As positive control for the reaction, positive samples for calicivirus, kindly provided by the Comparative Virology Laboratory at Fiocruz-Rio de Janeiro, Brazil, were used. Sterile milli-Q water was used as negative control. The recommended PCR precautions were carried out against false positives.

Statistical analysis - The statistical analysis was carried out using the EpiInfo software, version 6. The statistical significance of the data was determined by either the chi-square $\left(\chi^{2}\right)$ test or Fisher test and a probability of $<0.05$ was regarded as significant.

\section{RESULTS}

Table I shows the age-related positivity percentages for calicivirus by city of sample collection. An overall positivity percentage of $8.6 \%$ was observed. When cities of collection are taken into account, rates of 11.6 and $1.9 \%$ were observed in fecal specimens from children in Goiânia and Brasília, respectively $(\mathrm{p}<0.05)$. The age-related positivity analysis indicated a similar occurrence of calicivirus for every age group $(p>0.05)$.

There was no gender difference regarding calicivirus positivity (male - 42/751 - 7.3\%; female - 44/430 -
$10.2 \%)\left(\chi^{2}=2.23 p=0.1351\right)$. The analysis of the major gastroenteritis symptoms presented by the children from Goiânia, showed that all the children had diarrhea and there was no increase in calicivirus detection when other symptoms occurred in association with diarrhea $(\mathrm{p}>$ $0.05)$.

Calicivirus was detected in every month of the study although a peak of significant occurrence was observed during the rainy season, from September to March, in the city of Goiânia (Table II).

Calicivirus positivity of $52.9 \%$ (46/87) and $47.1 \%$ (41/ 87) was observed using primer pairs $289 / 290$ and $\mathrm{Ni} / \mathrm{E} 3$ or JV12/13, respectively.

\section{DISCUSSION}

Although studies about calicivirus have been carried out in different regions of the world, their aim has been mainly to detect NoVs. Therefore, the prevalence of human calicivirus is underestimated or even unknown, particularly in developing countries (Nakata et al. 2000, Gallimore et al. 2004). In the present study, an overall positivity rate of $8.6 \%$ for calicivirus was observed for children from two cities located in the West Central region of Brazil. Analyses considering the cities of collection shows that viral detection rates vary significantly, and the higher infection rate was observed in children from Goiânia. Our findings are in agreement with other studies carried out with similar population groups and using the same detection methodology, which showed rates from 5.5 to $24.2 \%$ (Bon et al. 1999, Farkas et al. 2000, Bereciartu et al. 2002, Buesa et al. 2002). In Brazil, calicivirus studies are still initial and all of them differ from this study. In this way, the study performed in Rio de Janeiro was carried out in daycare centers during outbreaks of acute gastroenteritis (Gallimore et al. 2004). The study carried out in Pará, used a different methodology for viral detection with the Amazon Amerindian population, which showed 100\% seroprevalence (Gabbay et al. 1994). The study performed in São Paulo used immune electron microscopy and reported a $1 \%$ calicivirus detection rate in children with acute gastroenteritis (Timenetsky et al. 1993). Finally, a study carried out in Ceará aimed to define NoV genomic diversity, which reported ten positive children for the Norwalk virus in a cohort of 120 children (Parks et al. 1999).

TABLE I

Percentage of calicivirus samples obtained from fecal specimens of children with acute gastroenteritis according to age and city of collection

\begin{tabular}{|c|c|c|c|c|c|c|}
\hline \multirow[b]{2}{*}{ Age range (months) } & \multicolumn{2}{|c|}{ Goiânia } & \multicolumn{2}{|c|}{ Brasília } & \multicolumn{2}{|c|}{ Total } \\
\hline & No. & $(\%)$ & No. & $(\%)$ & No. & $(\%)$ \\
\hline$\leq 6^{a}$ & $16 / 149$ & $(10.7)$ & $1 / 85$ & $(1.2)$ & $17 / 234$ & (7.3) \\
\hline $7-12$ & $33 / 277$ & (11.9) & $1 / 88$ & $(1.1)$ & $34 / 365$ & (9.3) \\
\hline $13-24$ & $15 / 140$ & (10.7) & $1 / 84$ & $(1.2)$ & $16 / 224$ & (7.1) \\
\hline $25-36$ & $7 / 62$ & (11.3) & $1 / 24$ & $(4.2)$ & $8 / 86$ & (9.3) \\
\hline$>36$ & $8 / 57$ & (14.0) & $1 / 24$ & $(4.2)$ & $9 / 81$ & (11.1) \\
\hline IU & $2 / 11$ & $(18.2)$ & $1 / 5$ & $(20.0)$ & $3 / 16$ & $(18.7)$ \\
\hline Total & $81 / 696$ & $(11.6)^{b}$ & $6 / 310$ & (1.9) & $87 / 1006$ & (8.6) \\
\hline
\end{tabular}

IU: information unavailable; $a: \chi^{2}=0.16 ; \mathrm{p}=0.688 ; b: \chi^{2}=24.34 ; \mathrm{p}=0.000$. 
TABLE II

Percentage of calicivirus obtained from fecal samples from children with acute gastroenteritis in relation to two different climatological seasons of the year, by city of collection

\begin{tabular}{|c|c|c|c|c|c|c|}
\hline \multirow[b]{2}{*}{$\underline{\text { Period }}$} & \multicolumn{2}{|c|}{ Goiânia } & \multicolumn{2}{|c|}{ Brasília } & \multicolumn{2}{|c|}{ Total } \\
\hline & No. & $(\%)$ & No. & $(\%)$ & No. & $(\%)$ \\
\hline $\begin{array}{l}\text { Sep - Mar } \\
\text { Apr - Aug }\end{array}$ & $\begin{array}{l}59 / 401 \\
22 / 295\end{array}$ & $\begin{array}{c}(14.7)^{b} \\
(7.4)\end{array}$ & $\begin{array}{c}6 / 234 \\
0 / 76\end{array}$ & $\begin{array}{l}(2.6)^{c} \\
(0.0)\end{array}$ & $\begin{array}{l}65 / 635 \\
22 / 371\end{array}$ & $\begin{array}{c}(10.2)^{a} \\
(5.9)\end{array}$ \\
\hline
\end{tabular}

$a: \chi^{2}=4.91 ; \mathrm{p}=0.02665 ; b: \chi^{2}=8.01 ; \mathrm{p}=0.00465 ; c$ : Fisher's exact test $\mathrm{p}=0.3419$.

The differences in positivity for calicivirus considering the cities of the study, need to be analyzed with caution once that five of the six positive Brasília samples were collected in the first period (1994-1995), when all samples were "in natura", whereas in the 2000-2002 period, the samples were collected by a rectal swab, which could have made it difficult the virus detection. Similar fact was observed in regard to astrovirus (Cardoso DDP, pers. commun.).

Calicivirus was detected in both genders and in all age groups. A similar occurrence of these viruses in male and female children in different age groups is described in the literature (Kaplan et al. 1982) although there is a higher rate of occurrence of these viruses in children up to 12 months of age (Pang et al. 1999, Rockx et al. 2002, Hansman et al. 2004).

Diarrhea has been considered the most common symptom among the adult population while vomiting occurs mainly in children infected with calicivirus (Kaplan et al. 1982). In this study, all the children had diarrhea, and there was also a high occurrence of vomiting and/or fever. Analysis of calicivirus in relation to symptomatology did not show difference between children who presented only diarrhea and those who presented other symptoms. These data agree with those from other studies (Kaplan et al. 1982, Becker et al. 2000, Rockx et al. 2002).

Several studies show the occurrence of calicivirus, mainly NoV, during the colder months of the year (Xi et al. 1990, Inouye et al. 2000, Mounts et al. 2000), while other show the circulation of these agents at different periods (Wright et al. 1998, Greening et al. 2001). The climate in the West Central region is sub-tropical and in Goiânia, temperatures are almost invariable throughout the year. Furthermore, September to March and August to April are considered the rainy and dry season, respectively (Cardoso et al. 2003). In the present study, the occurrence of calicivirus was observed throughout the year. However, higher incidence rates were observed between the months of September and March. We consider that this seasonality is related to higher atmospheric air humidity, as occurs with astrovirus (Cardoso et al. 2002). On the other hand, these data contrast with results concerning rotavirus circulation in Goiânia (April-August) (Cardoso et al. 2003).

The great genomic diversity presented by these viruses makes it difficult to choose specific primers for the detection of all genogroups. In addition, primers designed for the RNA polymerase region are largely used since this region is highly conserved (Wang et al. 1994, Green et al. 1997, Greening et al. 2001, Schuffenecker et al. 2001, Farkas et al. 2004). In this context, in the present study three primer pairs designed for that region were used. The positivity analysis for these viruses in relation to the primers used showed a similar percentage of detection. This data led us to reinforce the need for more than one specific primer pair for better detection of these viral agents and also of the two genera of human interest (Jiang et al. 1999, Guo et al. 2001).

Of 87 samples that were positive for calicivirus, ten were also positive for group A rotavirus (RV) and six for astrovirus, a fact which makes it difficult to define the causal agent of the infection. Other authors have reported similar results (Wolfaardt et al. 1997, Bon et al.1999, Bereciartu et al. 2002).

The results of this study show that caliciviruses occur in infant populations presenting acute gastroenteritis, and according to previous studies carried out in the region they are second to $\mathrm{RV}$ in occurrence (Cardoso et al. 2000, 2002, 2003). Finally, it is our understanding that more studies need to be carried out throughout the country for better knowledge about the occurrence of these viruses and in order to adopt future preventive measures.

\section{REFERENCES}

Ando T, Noel JS, Frankhauser RL 2000. Genetic classification of "Norwalk-like viruses". J Infect Dis 181: S336-348.

Becker KM, Moe CL, Southwick KL, Maccormack JN 2000. Transmission of Norwalk virus during a football game. N Engl J Med 343: 1223-1227.

Bereciartu A, Bok K, Gómez J 2002. Identification of viral agents causing gastroenteritis among children in Buenos Aires, Argentina. J Clin Virol 25: 197-203.

Bon F, Fascia P, Dauvergne M, Tenenbaum D, Planson H, Petion AM, Pothier P, Kohli E 1999. Prevalence of group A rotavirus, human calicivirus, astrovirus, and adenovirus type 40 and 41 infections among children with acute gastroenteritis in Dijon, France. J Clin Microb 37: 3055-3058.

Boom R, Sol CJA, Salimans MMM, Jansen CL, Dillen PMEW, Noordaa J 1990. Rapid and simple method for purification of nucleic acids. J Clin Microb 28: 495-503.

Buesa J, Collado B, López-Andújar P, Abu-Mallouh R, Díaz JR, Díaz AG, Prat J, Guix S, Llovet T, Prats G, Bosch A 2002. Molecular epidemiology of caliciviruses causing outbreaks and sporadic cases of acute gastroenteritis in Spain. J Clin Microb 40: 2854-59.

Cardoso DDP, Soares CMA, Azevedo MSP, Leite JPG, Munford 
V, Rácz ML 2002. Serotypes and subgroups of rotavirus isolated from children in Central Brazil. Med Sci Monit 8: CR624-628.

Cardoso DDP, Soares CMA, Fiaccadori FS, Souza MBLD, Martins RMB, Leite JPG, Munford V, Rácz ML 2000. Detection and genotyping of astroviruses from children with gastroenteritis from Goiânia, Goiás, Brazil. J Health Popul Nutr 18: 39-43.

Cardoso DDP, Soares CMA, Souza NBLD, Azevedo MSP, Martins RMB, Queiroz DAO, Brito WNED, Munford V, Rácz ML 2003. Epidemiological features of rotavirus infection in Goiânia, Goiás, Brazil, from 1986 to 2000. Mem Inst Oswaldo Cruz 98: 25-29.

Farkas T, Jiang X, Guerrero ML, Zhong W, Wilton N, Berke T, Matson DO, Pickering LK, Ruiz-Palacios G 2000. Prevalence and genetic diversity of human caliciviruses (HuCVs) in Mexican children. J Med Virol 62: 217-223.

Farkas T, Zhong W, Jing Y, Huang PW, Espinosa SM, Martinez N, Morrow AL, Ruiz-Palacios G, Pickering LK, Jiang X 2004. Genetic diversity among sapoviruses. Arch Virol 149: 13091323.

Gabbay YB, Glass RI, Monroe SS, Carcamo C, Estes MK, Mascarenhas JD, Linhares AC 1994. Prevalence of antibodies to Norwalk virus among Amerindian isolated Amazonian communities. Am J Epidemiol 139: 738-743.

Gallimore CI, Barreiros MAB, Brown DWG, Nascimento JP, Leite JPG 2004. Norovirus associated with acute gastroenteritis in a children's day care facility in Rio de Janeiro, Brazil. Bras $J$ Med Biol Research 37: 321-326.

Glass PJ, White LJ, Ball JM, Lepare-Goffart I, Hardy ME, Estes MK 2000. Norwalk virus open reading frame 3 encodes a minor structural protein. J Virol 74: 6581-6591.

Gray JJ, Green J, Cunliffe C, Gallimore C, Lee JV, Neal K, Brown DWG 1997. Mixed genogroup SRSV infections among a party of canoeists exposed to contaminated recreational water. $J$ Med Virol 52: 425-429.

Greening GE, Mirams M, Berke T 2001. Molecular epidemiology of "Norwalk-like viruses" associated with gastroenteritis outbreaks in New Zealand. J Med Virol 64: 58-66.

Green J, Gallimore CI, Norcott JP, Lewis D, Brown DWG 1995. Broadly reactive reverse transcriptase polymerase chain reaction for the diagnosis of SRSV - associated gastroenteritis. J Med Virol 47: 392-398.

Green KY, Ando T, Balayan MS, Berke T, Clarke IN, Estes MK, Matson DO, Nakata S, Neil JD, Studdert MJ, Thiel H-J 2000. Taxonomy of the caliciviruses. J Infect Dis 181: S322-330.

Green SM, Lambden PR, Caul EO, Clarke IN 1997. Capsid sequence diversity in small round structured viruses from recent UK outbreaks of gastroenteritis. J Med Virol 52: 1419.

Guo M, Qian Y, Chang KO, Saif LJ 2001. Expression and selfassembly in baculovirus of porcine enteric calicivirus capsids into virus-like particles and their use in an enzyme-linked immunosorbent assay for antibody detection in swine. J Clin Microb 39: 1487-1493.

Hansman GS, Katayama K, Maneekarn N, Peerakome S, Khamrin P, Tonusin S, Okitsu S, Nishio O, Takeda N, Ushijima H 2004. Genetic diversity of norovirus and sapovirus in hospitalized infants with sporadic cases of acute gastroenteritis in Chiang Mai, Thailand. J Clin Microb 42: 1305-1307.
Inouye S, Yamashita K, Yamadera S, Yoshika WAM, Kato N, Okabe N 2000. Surveillance of viral gastroenteritis in Japan: pediatric cases and outbreak incidents. J Infec Dis 181: S270-274.

Jiang X, Espul C, Zhong WM, Cuello H, Matson DO 1999. Characterization of a novel human calicivirus that may be a naturally occurring recombinant. Arch Virol 144: 2377-2387.

Kaplan JE, Gary GW, Baron RC, Singh N, Schonberger LB, Feldman R, Greenberg HB 1982. Epidemiology of Norwalk gastroenteritis and the role of Norwalk virus in outbreaks of acute gastroenteritis. Ann Inter Med 96: 756-761.

Koopmans M, BonsdorffC-H, Vinjé J, Medici D, Monroe S 2002. Foodborne viruses. FEMS Microbiol Rev 26: 187-205.

Mounts AW, Ando T, Koopmans M, Bresee JS, Noel J, Glass RI 2000. Cold weather seasonality of gastroenteritis associated with Norwalk-like viruses. J Infect Dis 181: S284-287.

Nakata S, Honma S, Numata K, Kogawa K, Ukae S, Morita Y, Adachi N, Chiba S 2000. Members of the family Caliciviridae (Norwalk virus and Sapporo virus) are the most prevalent cause of gastroenteritis outbreaks among infants in Japan. $J$ Infect Dis 181: 2029-2032.

Pang X, Joensuu J, Vesikari T 1999. Human calicivirus-associated sporadic gastroenteritis in Finnish children less than two years of age followed prospectively during a rotavirus vaccine trial. Pediatric Infect Dis J 18: 420-426.

Parks CG, Moe CL, Rhodes D, Lima A, Barret L, Tseng F, Baric R, Talal A, Guerrant R 1999. Genomic diversity of "Norwalk like viruses" (NLVs): pediatric infections in a Brazilian shantytown. JMed Virol 58: 426-434.

Rockx B, Wit M, Vennema H, Vinjé J, Bruin E, Van Duynhoven, Koopmans M 2002. Natural history of human Calicivirus infection: a prospective cohort study. Clin Infec Dis 35: 246253.

Schuffenecker I, Ando T, Thouvenot D, Lina B, Aymard M 2001. Genetic classification of "Sapporo-like viruses". Arch Virol 146: 2115-2132.

Timenetsky MC, Kisielius JJ, Grisi SJ, Escobar AM, Ueda M, Tanaka H 1993. Rotavirus, adenovirus, astrovirus, calicivirus and small round virus particles in feces of children with and without acute diarrhea, from 1987 to 1988, in the greater São Paulo. Rev Inst Med Trop São Paulo 35: 275-280.

Vinjè J, Altena SA, Koopmans MPG 1997. The incidence and genetic variability of small round-structured viruses in outbreaks of gastroenteritis in the Netherlands. J Infect Dis 176: 1374-1378.

Wang J, Xi J, Madore HP, Gray J, Desselberger U, Ando T, Seto Y, Oishi I, Lew JF, Green KY, Estes MK 1994. Sequence diversity of small, round-structured viruses in the Norwalk virus group. J Virol 68: 5982-5990.

Wolfaardt M, Taylor MB, Booysen HF, Engelbrecht L, Grabow WOK, Jiang S 1997. Incidence of human calicivirus and rotavirus infection in patients with gastroenteritis in South Africa. J Med Virol 51: 290-296.

Wright PJ, Gunesekere IC, Doultree JC, Marshall JA 1998. Small round-structured (Norwalk-like) viruses and classical human caliciviruses in southeastern Australia, 1980-1996. JMed Virol 55: 312-320.

Xi JN, Graham DY, Wang KN, Estes MK 1990. Norwalk virus genome cloning and characterization. Science 250: 15801583. 